\title{
Compositional and engineering adaptations in dentine explored by analytical STEM
}

Vesna Srot ${ }^{1}$, Birgit Bussmann ${ }^{1}$, Boštjan Pokorny ${ }^{2,3}$, Masashi Watanabe ${ }^{4}$ and Peter A. van Aken ${ }^{1}$

${ }^{1 .}$ Stuttgart Center for Electron Microscopy, Max Planck Institute for Solid State Research, Stuttgart, Germany.

2. Environmental Protection College + Eurofins ERICo, Velenje, Slovenia.

${ }^{3 .}$ Slovenian Forestry Institute, Ljubljana, Slovenia.

4. Department of Materials Science and Engineering, Lehigh University, Bethlehem PA, USA.

Mammalian teeth are a composite product of biomineralization composed of an inorganic component, hydroxyapatite (HA), and an organic component, predominantly collagen. Although teeth show high degree of diversity in form and size, their basic structure and composition are identical. Biologically formed HA never appears as pure component but rather as structurally and compositionally sophisticated and precisely adjusted Ca-deficient carbonate containing apatite modified with minor amounts of $\mathrm{Mg}, \mathrm{Na}, \mathrm{K}$ and $\mathrm{Zn}$ [1]. Three main unique hard dental tissues - enamel, dentine and cementum, are combined into one structural unit. Dentine is the most voluminous tissue, consisting of $70 \mathrm{wt} \%$ of inorganic HA platelets, $20 \mathrm{wt} \%$ of organic material, and $10 \mathrm{wt} \%$ of water that is forming the bulk of the tooth [2]. It is intersected by numerous dentinal tubules (DT), turning it into a very permeable composite tissue [2,3]. Characterisation of biological functional composites is an extremely challenging task due to high architectural diversity and extreme electron beam sensitivity.

In our study, the microstructure and nanoscale chemistry of dentine and dentinal tubules (DT) in human teeth [4], molars and continuously growing incisors of a selected rodent species, i.e. coypu (Myocastor coypus) [5] were investigated by advanced analytical and imaging transmission electron microscopy (TEM) techniques. Cross-sectional view of human premolar and coypu's incisor are presented in Figure 1a and 1d, respectively. In human teeth, a relatively dense rim of peritubular dentine (PD) surrounding the DT was observed, while the bulk of dentine between the DT is consisting of intertubular dentine (ID) (Figure $1 \mathrm{~b}, 1 \mathrm{c})$. We have detected significantly higher $\mathrm{Mg} / \mathrm{P}$ at $\%$ ratios in the $\mathrm{PD}$ rim ( 1.4 times) compared to the values measured in ID, while the average $\mathrm{Ca} / \mathrm{P}$ at $\%$ ratios are higher in ID (Figure 2). It is very likely that $\mathrm{Mg}$ is incorporated into the HA lattice when considering the crystal chemistry. Additionally, the presence of smaller HA crystals in PD could be associated with higher $\mathrm{Mg}$ concentrations.

Interestingly, the ID of human teeth and coypu's molars are chemically identical (Figure 2). Flake-like amorphous material was found in DT of rodents incisors, whereas no PD was found surrounding the DT (Figure 1e). The amount of Mg present in the ID of incisors is notably higher (Figure 2). Strikingly, the flake-like material present within the DT of coypu's incisors contains an unprecedentedly high amount of $\mathrm{Mg}$ that is around 5 times higher compared to the values for ID (Figure 2), suggesting the presence of a (Mg, Ca)-phosphate phase. Such high amounts of Mg have never been detected before in dental and skeletal tissues and could be closely correlated with the permanent growth of rodent's incisors.

\section{References:}

[1] S Mann, Biomineralization; Oxford University Press: Oxford, UK, 2001

[2] JK Avery, Essentials of Oral Histology and Embryology; Mosby Elsevier, USA, 2006

[3] IA Mjör and I Nordahl, Arch Oral Biol 41 (1996), 401 
[4] V Srot et al., Microsc Microanal 18 (2012), 509

[5] V Srot et al., ACS Nano 11 (2017), 239
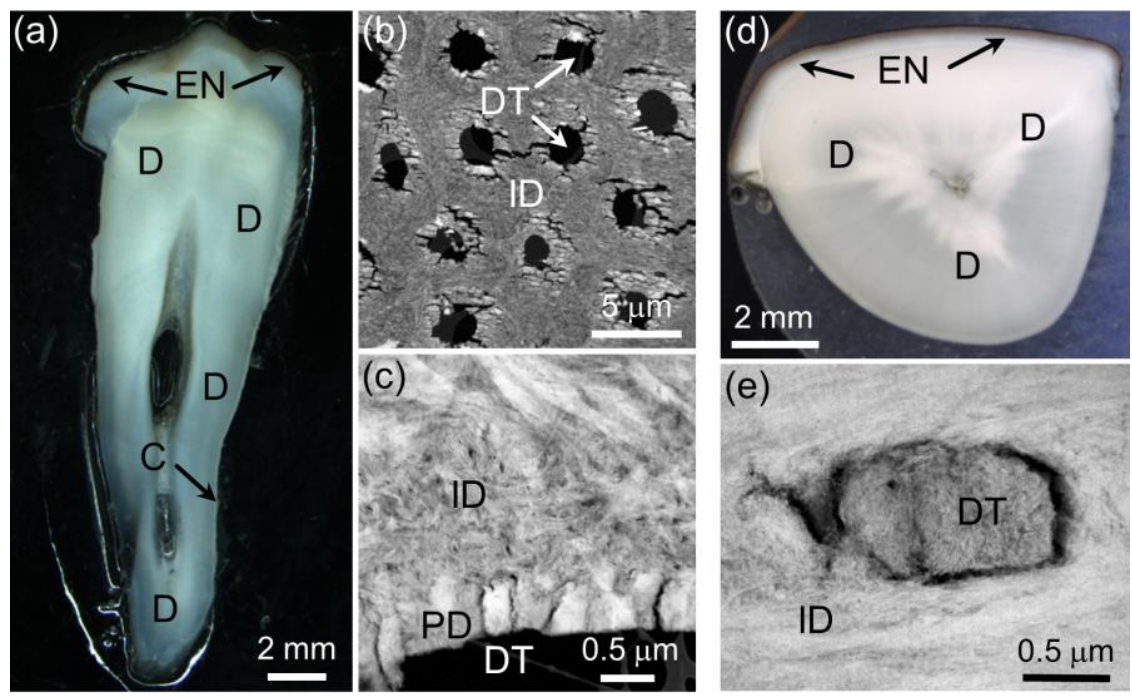

Figure 1. (a) Optical micrograph of a longitudinal cross-section of the human permanent maxillary premolar with marked positions of enamel (EN), dentine (D) and cementum (C). (b) Low-magnification ADF-STEM image showing dentinal tubules (DT) separated by intertubular dentine (ID). (c) ADFSTEM image of enlarged peritubular dentine (PD) rim that is surrounding DT. (d) Optical micrograph of a coypu's incisor cross-section. (e) HAADF-STEM image of DT filled with flake-like material and surrounded by ID.

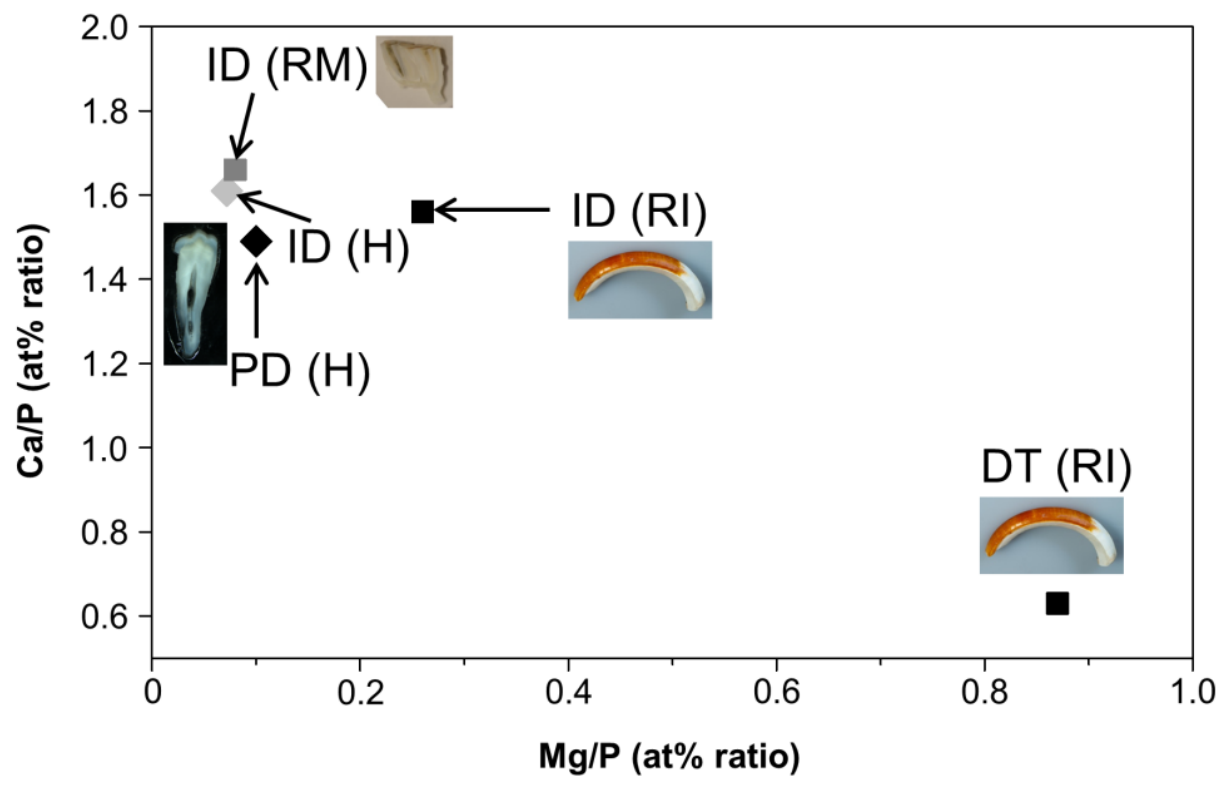

Figure 2. $\mathrm{Ca} / \mathrm{P}$ at $\%$ ratio plotted against the corresponding $\mathrm{Mg} / \mathrm{P}$ at $\%$ ratio measured in intertubular dentine (ID) and peritubular dentine (PD) of human teeth (H), in ID and dentinal tubules (DT) of coypu's incisors (RI), and in ID of coypu's molar (RM). 